\title{
Biodiversity hotspots: Natural regeneration dynamics of threatened Dacrydium pectinatum communities along various environmental axes on Hainan Island, China
}

\author{
Haodong Liu ${ }^{1}$, Qiao Chen ${ }^{1}$, Yongfu Chen ${ }^{1}$, Zhiyang $\mathrm{Xu}^{1}$, Yunchuan Dai ${ }^{2}$, Yang $\mathrm{Liu}^{1}$, Yi \\ Jiang ${ }^{1}$, Xi Peng ${ }^{1}$, Huayu Li $^{1}$, Juan Wang ${ }^{1}$, and Hua Liu ${ }^{1}$ \\ ${ }^{1}$ Affiliation not available \\ ${ }^{2}$ Chinese Academy of Forestry
}

May 6, 2020

\begin{abstract}
Exploring the dynamics of natural regeneration facilitates the understanding of the mechanisms of community assembly and biodiversity formation in tropical forests. However, there is still a lack of convincing evidence related to regeneration, especially for threatened tropical plant communities. Dacrydium pectinatum is a constructive and an endangered species in the tropical mountain forests of Hainan Island. A total of 204 regeneration plots of $5 \mathrm{~m} \times 5 \mathrm{~m}$ were investigated along environmental axes of temperature and precipitation in the northwest (Bawangling, 90 plots), southwest (Jianfengling, 90 plots) and southeast (Diaoluoshan, 24 plots) of Hainan Island. We examined the variation in community structure, mortality, density and species richness at the three sites and analyzed the key environmental drivers that affect regeneration. The results showed that the mortality of adults, seedlings and saplings was the lowest in Diaoluoshan, followed by Jianfengling and Bawangling. The peaks in the density and species richness of regenerating individuals were limited to mid-elevations. Elevation, soil total nitrogen, soil available phosphorus, canopy density and adult density were significantly correlated with density and species richness. All findings indicate that at a broad landscape scale, variation in precipitation and temperature due to latitude, longitude and elevation is the dominant cause for the formation of the regeneration dynamic patterns along distinct environmental axes and that the intermediate environmental conditions at middle elevations contribute to regeneration. At the community level, habitat preferences related to elevational factors, soil total nitrogen, soil available phosphorus and forest gaps play a key role in regeneration success. Biological mechanisms (negative density-limiting effects) also have an important effect. We recommend various actions to improve the protection of D. pectinatum, such as the prevention of habitat destruction, appropriate thinning of high-density stands, and strengthening of niche research, and increase biodiversity.
\end{abstract}

Biodiversity hotspots: Natural regeneration dynamics of threatened Dacrydium pectinatumcommunities along various environmental axes on Hainan Island, China

Haodong Liu ${ }^{\mathrm{a}}$, Qiao Chen ${ }^{\mathrm{a}}$, Yongfu Chen ${ }^{\mathrm{a}}$, Zhiyang Xu ${ }^{\mathrm{b}}$, Yunchuan Dai ${ }^{\mathrm{c}}$, Yang Liu ${ }^{\mathrm{a}}$, Yi Jiang ${ }^{\mathrm{a}}$, Xi Peng ${ }^{\mathrm{d}}$, Huayu Li ${ }^{\mathrm{e}}$, Juan Wang ${ }^{\mathrm{e}}$, Hua Liu ${ }^{\mathrm{a}^{*}}$

${ }^{a}$ Research Institute of Forest Resource Information Techniques, Chinese Academy of Forestry, Beijing, 100091, China

b East China Inventory and Planning Institute of National Forestry and Grassland Administration, Hangzhou, 321000, Zhejiang, China

${ }^{\mathrm{c}}$ Research Institute of Forest Ecology, Environment and Protection, Chinese Academy of Forestry, Beijing, 100091, China 
d College of Forestry, Sichuan Agricultural University, Chengdu Sichuan 611130, China

e College of Forestry, Southwest Forestry University, Kunming Yunnan 650233, China

* Corresponding author, Hua Liu. Research Institute of Forest Resource Information Techniques, Chinese Academy of Forestry, Beijing, 100091, China

Tel: +86-010-6288-9258

Email: liuhua@caf.ac.cn

Biodiversity hotspots: Natural regeneration dynamics of threatenedDacrydium pectinatum communities along various environmental axes on Hainan Island, China

\begin{abstract}
Exploring the dynamics of natural regeneration facilitates the understanding of the mechanisms of community assembly and biodiversity formation in tropical forests. However, there is still a lack of convincing evidence related to regeneration, especially for threatened tropical plant communities. Dacrydium pectinatum is a constructive and an endangered species in the tropical mountain forests of Hainan Island. A total of 204 regeneration plots of $5 \mathrm{~m} \times 5 \mathrm{~m}$ were investigated along environmental axes of temperature and precipitation in the northwest (Bawangling, 90 plots), southwest (Jianfengling, 90 plots) and southeast (Diaoluoshan, 24 plots) of Hainan Island. We examined the variation in community structure, mortality, density and species richness at the three sites and analyzed the key environmental drivers that affect regeneration. The results showed that the mortality of adults, seedlings and saplings was the lowest in Diaoluoshan, followed by Jianfengling and Bawangling. The peaks in the density and species richness of regenerating individuals were limited to mid-elevations. Elevation, soil total nitrogen, soil available phosphorus, canopy density and adult density were significantly correlated with density and species richness. All findings indicate that at a broad landscape scale, variation in precipitation and temperature due to latitude, longitude and elevation is the dominant cause for the formation of the regeneration dynamic patterns along distinct environmental axes and that the intermediate environmental conditions at middle elevations contribute to regeneration. At the community level, habitat preferences related to elevational factors, soil total nitrogen, soil available phosphorus and forest gaps play a key role in regeneration success. Biological mechanisms (negative densitylimiting effects) also have an important effect. We recommend various actions to improve the protection of D. pectinatum, such as the prevention of habitat destruction, appropriate thinning of high-density stands, and strengthening of niche research, and increase biodiversity.
\end{abstract}

Key words: Biodiversity hotspots; Biodiversity conservation;Dacrydium pectinatum ; Natural regeneration; Hainan Island

\title{
1. Introduction
}

One of the oldest research aims in ecology is exploring the natural regeneration process of woody plants, which facilitates the understanding of species maintenance and assembly mechanisms in communities (Jarcuska 2009; Vizoso-Arribe et al. 2014). It is generally accepted that regeneration plays an important role in the composition, structure, and diversity of plant communities and ultimately determines the ecosystem service functions of forest environments (Miller et al. 2017; Zhu 2017). Nevertheless, the transition from seedling to sapling has been seen as a bottleneck in tree establishment (Yan et al. 2015), and many tree species may experience regeneration failures early in community succession (Collins and Carson 2004; Peña-Claros et al. 2008; Du et al. 2007). As a consequence, exploring the ecological processes that drive natural regeneration and their relative contributions, especially in highly diverse and threatened tropical forest ecosystems, remains a major challenge for ecologists.

In recent years, a number of hypotheses have sought to explain the mechanisms of regeneration. Resourcebased niche partitioning is one of the widely discussed mechanisms contributing to regeneration (Satoh et al. 2015; Kitching and Roger 2013) and suggests that species undergo niche partitioning in association with specific abiotic environment combinations (light, soil nutrients, and water) to promote the coexistence and maintenance of species diversity (Chesson 2000; Adler et al. 2007; Jurinitz et al. 2013). Such available 
resource preferences among species also cause regeneration to exhibit different spatial change patterns along various environmental axes (Bai et al. 2012). Negative density dependence is also an important theory explaining regeneration dynamics (Suter et al. 2010). Under the assumptions of the Janzen-Connell (J-C) hypothesis, a decline in natural enemies and uneven competition for restricted resources might reduce the survival and recruitment of seedlings when they occur in localized areas with high conspecific density (Connell 1978; Janzen 1970). In general, the positive density dependence explained by environmental factors and the negative density dependence represented by the J-C effect may simultaneously play a role in regeneration dynamics. Thus, the contributions of biological factors simultaneously affecting seedling recruitment cannot be ignored when exploring the relationship between environmental factors and regeneration patterns.

Previous research has shown that the natural regeneration of plant communities is closely related to differences in environmental conditions and that saplings are more susceptible to biotic/abiotic factors than adults in old-growth tropical and subtropical forests (Queenborough et al. 2009; Jiang et al. 2016), where both a significant degree of variation and a large degree of overlap in microhabitat suitability among species exist (Kraft et al. 2008; Song et al. 2018). Large numbers of tree species might have specific light, nutrient and topography requirements for regeneration in diverse tropical and subtropical forests (Jin et al. 2018; Laurans et al. 2012). However, there are also studies supporting the idea of incomplete filtering, showing that tree species regeneration is not very sensitive to available resources (Dechnik-Vázquez et al. 2016). Given these contrasting results, there is still a lack of compelling data on the drivers contributing to regeneration, especially for threatened plant communities in tropical forests. Consequently, it is necessary to focus on the regeneration dynamics in plant communities and their driving factors along various environmental axes, particularly in tropical mountain forests on Hainan Island, China, where there has been no distinct conclusion regarding this topic.

Hainan Island in China is floristically rich and has been listed as an internationally significant "hotspot" area for biodiversity conservation (Myers et al. 2000). Based on current records, approximately 4,600 woody plants have been recorded, and 397 of these plants are endemic to the island (Francisco-Ortega et al. 2010).Dacrydium pectinatum is one of the constructive and endangered species in the tropical mountain forests of Hainan Island and belongs to the Podocarpaceae family (Keppel et al. 2011). According to our previous investigation, natural communities shaped by $D$. pectinatum as a canopy tree species are usually highly diverse. Currently, this species appears to have become extinct in Australia during the Miocene (Norton et al. 1988; Wu et al. 2019). D. pectinatum is the only species of this genus that exists in China, and it is found only in four original tropical rainforests on Hainan Island, namely, Bawangling, Jianfengling, Diaoluoshan and Wuzhishan (Huang et al. 2014). Here, we present a detailed investigation of the composition of seedlings and saplings and environmental factors in D. pectinatum communities along the environmental axes of air temperature and precipitation across three national nature reserves in Bawangling, Diaoluoshan, and Jianfengling on Hainan Island, China. Specifically, we hypothesize that in addition to abiotic factors, such as light and topography, biotic mechanisms, such as negative density dependence, can also affect the regeneration dynamics of the $D$. pectinatum community. We asked the following questions: (1) How do the dynamics of natural regeneration change along environmental gradients? (2) What drivers play a key role in contributing to regeneration, and can we find a direct or indirect effect on these drivers from niche partitioning and negative density dependence? We also hope that this study will highlight the gaps in biodiversity conservation knowledge regarding endangered plant communities in tropical forests.

\section{Materials and Methods}

\subsection{Site description}



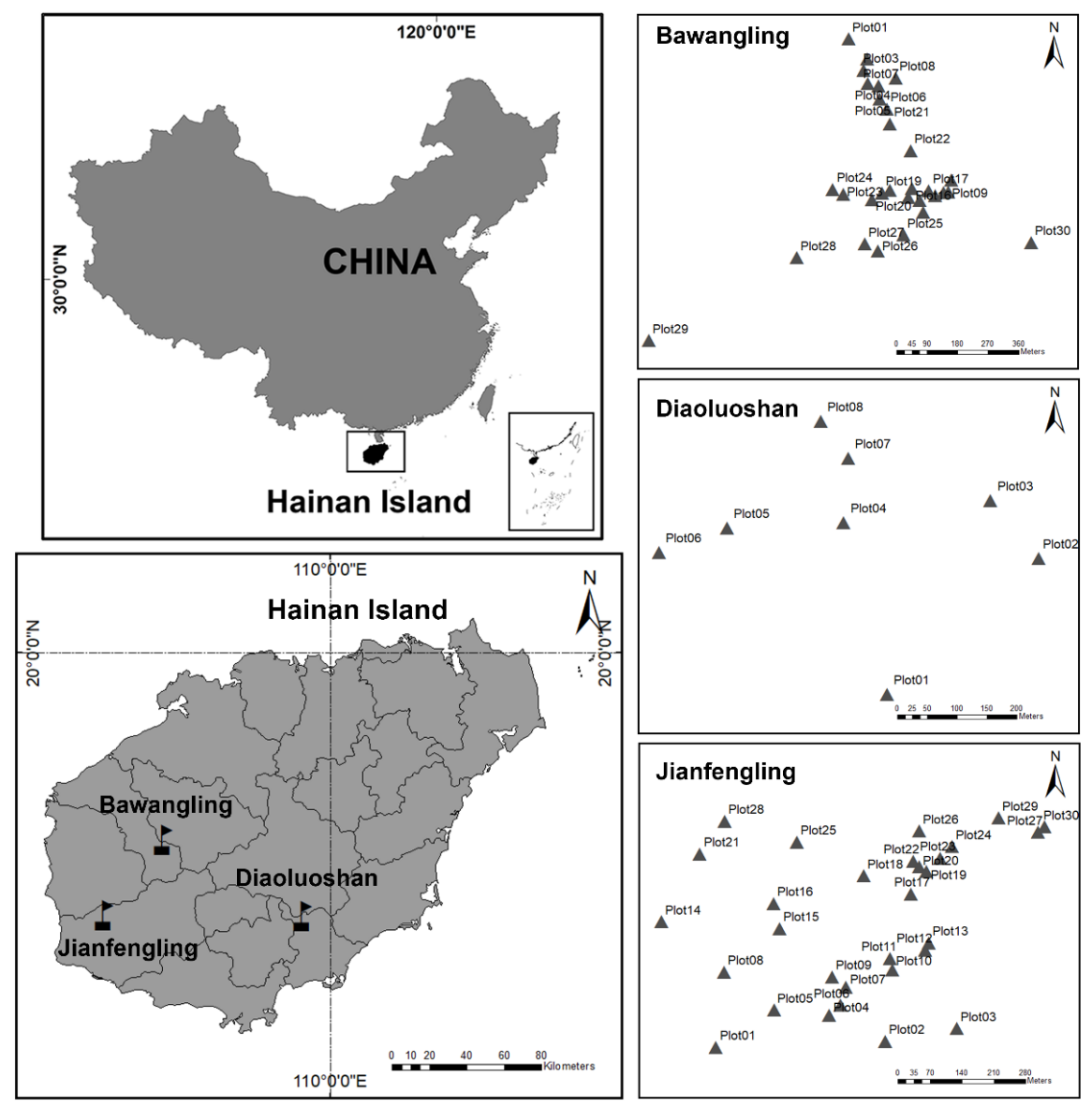

Figure 1. Permanent plot locations in the natural D. pectinatum communities in the three national nature reserves of Bawangling, Diaoluoshan and Jianfengling, Hainan Island, China.

Hainan Island is located at the northern edge of tropical Asia. The topography is higher in the middle than around the edges of the island. The average annual precipitation decreases from east to west, and the annual average temperature decreases from south to north. The southwest and west are affected by the ocean monsoon, and there are obvious wet and dry seasons. More clouds and lower temperatures occur in the central mountainous region than elsewhere on the island. The study was conducted along three environmental axes (i.e., precipitation and temperature gradients) in Bawangling, which is located in the southwestern part of Hainan Island (1853'-19deg20'N, 108deg58'-109deg53'E), Diaoluoshan, which is situated in the southeastern part of Hainan Island (18deg43'-18deg58'N, 109deg43'-110deg03'E), and Jianfengling, which is located in the southwestern part of Hainan Island (18deg23'-18deg50' N, 108deg36'-109deg05'E). These areas are national nature reserves in China.

The total area of the Bawangling Nature Reserve is approximately $72,000 \mathrm{hm}^{2}$. It has a tropical monsoon climate, the annual mean temperature is $23.6 \mathrm{degC}$, and the annual mean precipitation is between 1500 and $2000 \mathrm{~mm}$. The total area of the Diaoluoshan Nature Reserve is approximately $37,900 \mathrm{hm}^{2}$. It has a marine tropical monsoon climate. The annual mean temperature is $24.4 \mathrm{degC}$, and the annual mean precipitation is between $1870 \mathrm{~mm}$ and $2760 \mathrm{~mm}$. The total area of the Jianfengling Nature Reserve is approximately 640 $\mathrm{km}^{2}$, and it has a monsoon climate typical of tropical islands at low latitudes. The annual mean temperature is between $19.7 \mathrm{degC}$ and $25.2 \mathrm{deg}$, and the annual precipitation is between $1600 \mathrm{~mm}$ and $2600 \mathrm{~mm}$.

The tropical mountain forests at the three sites are mainly distributed on mountaintops at elevations above 
$800 \mathrm{~m}$, and they are among the few well-preserved forest types with tropical rainforest properties in China. They constitute the northern boundary of the Southeast Asian tropical rainforests and represent a forest type that transitions from tropical rainforest to subtropical/warm temperate rainforest (Ding et al. 2012). This unique setting also allows these forests to play an irreplaceable role in research on tropical and subtropical rainforest ecology (Fang et al. 2004). They could also provide an ideal place to explore the natural regeneration dynamics of tropical forests. Hence, a total of sixty-eight permanent plots in the natural $D$. pectinatum communities were investigated, and the sampling information for the three sites is provided in Figure 1. Based on field investigations, detailed coordinate, climate (data from WorldClim-Global Climate Data (http://www.worldclim.org/ )) and topography data for the three sites are shown in Table 1.

Table 1. Topographic and climatic characteristics across the three study sites

\begin{tabular}{|c|c|c|c|c|c|c|c|c|}
\hline $\begin{array}{l}\text { Forest } \\
\text { type }\end{array}$ & Latitude & Latitude & Longitude & Longitude & Elevation & Elevation & $\begin{array}{l}\text { Annual } \\
\text { average } \\
\text { temperature }\end{array}$ & $\begin{array}{l}\text { Annual } \\
\text { average } \\
\text { temperature }\end{array}$ \\
\hline Bawangling & Bawangling & & & & & & & \\
\hline TMRF & $18^{\circ} 57^{\prime} \mathrm{N}$ & $18^{\circ} 57^{\prime} \mathrm{N}$ & $109^{\circ} 03^{\prime} \mathrm{E}$ & $109^{\circ} 03^{\prime} \mathrm{E}$ & \multirow{2}{*}{\multicolumn{3}{|c|}{$1155.78 \pm 56.93155 .78 \pm 56.930 .74 \pm 1.78^{\mathrm{a}}$}} & $20.74 \pm 1.78^{\mathrm{a}}$ \\
\hline Diaoluoshan & Diaoluoshan & & & & & & & \\
\hline $\begin{array}{l}\text { TMRF } \\
\text { Jianfengling }\end{array}$ & $\begin{array}{l}18^{\circ} 43^{\prime} \mathrm{N} \\
\text { lianfen }{ }^{2} \text { lino }\end{array}$ & $18^{\circ} 43^{\prime} \mathrm{N}$ & $109^{\circ} 43^{\prime} \mathrm{E}$ & $109^{\circ} 43^{\prime} \mathrm{E}$ & \multicolumn{3}{|c|}{$935.97 \pm 22.96935 .97 \pm 22.9621 .89 \pm 1.60^{\mathrm{b}}$} & $21.89 \pm 1.60^{\mathrm{b}}$ \\
\hline TMRF & $18^{\circ} 20^{\prime} \mathrm{N}$ & $18^{\circ} 20^{\prime} \mathrm{N}$ & $108^{\circ} 41^{\prime} \mathrm{E}$ & $108^{\circ} 41^{\prime} \mathrm{E}$ & \multicolumn{3}{|c|}{$907.43 \pm 46.54907 .43 \pm 46.5421 .75 \pm 1.52^{\mathrm{b}}$} & $21.75 \pm 1.52^{\mathrm{b}}$ \\
\hline
\end{tabular}

TMRF represents tropical mountain rainforest. Elevation $(\mathrm{m})$, annual average temperature $\left({ }^{\circ} \mathrm{C}\right)$, and annual average precipitation $(\mathrm{mm})$ are expressed as the mean $\pm \mathrm{sd}$.

\subsection{Field investigations}

Field investigations were conducted from December 2017 to July 2018. Based on a previous experimental design and the experience of local forestry workers, the selection criteria for each plot were as follows: (1) the plots must contain varying numbers of adult $D$. pectinatumindividuals, and $D$. pectinatum must be a canopy plant species; (2) the conditions within the stand must be relatively uniform and show limited human interference. if the location of the plot met the above criteria, a plot was randomly established within the stand. A total of sixty-eight $900 \mathrm{~m}^{2}(30 \mathrm{~m} \times 30 \mathrm{~m})$ permanent plots inD. pectinatum communities were investigated according to the minimum area sampling method in the western (Bawangling, 30 plots), southwestern (Jianfengling, 30 plots) and eastern (Diaoluoshan, 8 plots) parts of Hainan Island. Note: Due to severe deforestation at the Diaoluoshan site, we established only 8 permanent plots at this location. All woody stems (including trees, shrubs, and lianas) with a diameter at breast height (DBH) [?]5 cm were identified to the species level, tagged, and mapped, and their DBH was measured. The nomenclature follows that used in the Flora of China (http://foc.eflora.cn/ ).

In each $30 \mathrm{mx} 30 \mathrm{~m}$ plot, three $25 \mathrm{~m}^{2}(5 \mathrm{mx} 5 \mathrm{~m})$ subplots along the diagonal (upper left, middle, and bottom right) were also established to record the regeneration dynamics. In each $5 \mathrm{mx} 5 \mathrm{~m}$ regeneration plot, all free-standing woody plants $<5 \mathrm{~cm}$ in stem diameter were tagged and identified to the species level. Species were identified by local botanists, with nomenclature consistent with the Flora of China website (http://foc.eflora.cn/). Additionally, their health status, stem height and crown width were also measured. The regenerating individuals were considered those with emerged cotyledon leaves, indicating one-year-old plants (Gao et al. 2017). Data were ultimately collected for a total of 204 regeneration plots.

\subsection{Environmental factor measurement}

Soil samples were collected along the diagonal (upper left, middle, and lower right) in each of the $30 \times 30 \mathrm{~m}$ plots. A core of the top $20 \mathrm{~cm}$ of soil was taken at each point. Soil samples were mixed into a single sample and dried in the laboratory. After sieving, the physical and chemical indicators of the soil samples were 
measured in accordance with international standard methods. The indicators included soil organic matter (SOM, $\mathrm{g}^{*} \mathrm{~kg}^{-1}$, potassium dichromate oxidation volumetric method, LY/T 1237-1999), soil total nitrogen (TN, g* $\mathrm{kg}^{-1}$, Kjeldahl boiling-diffusion method, LY/T 1228-1999), soil available phosphorus (AP, mg* $\mathrm{kg}^{-1}$, $0.05 \mathrm{~mol}^{*} \mathrm{~L}^{-1} \mathrm{HCl}-0.025 \mathrm{~mol}^{*} \mathrm{~L}^{-1} 1 / 2 \mathrm{H}_{2} \mathrm{SO}_{4}$ extraction method, LY/T 1233-1999), soil available potassium (AK, mg* $\mathrm{kg}^{-1}, 1 \mathrm{~mol}^{*} \mathrm{~L}^{-1}$ ammonium acetate extraction flame photometry, LY/T 1236-1999) and soil $\mathrm{pH}$ ( $\mathrm{pH}, \mathrm{H}_{2} \mathrm{O}, 1: 2.5$, potentiometry, LY/T 1239-1999).

In each 30x30 m plot, elevation, latitude and longitude data were collected by a global positioning navigation system (GPS). In addition, stand characteristics (canopy and adult density) and other topographic factors (aspect, slope position and slope) were also recorded.

\subsection{Data analysis}

We compared the structural characteristics of the communities at the three sites on the basis of the size structure. According to our previous observations, the maximum DBH of woody plants in the studied $D$. pectinatum communities is typically greater than $60 \mathrm{~cm}$. Thus, we clustered the adult individuals into twelve size classes representing $5 \mathrm{~cm}$ intervals (i.e., $5 \mathrm{~cm}-10 \mathrm{~cm}, 10 \mathrm{~cm}-15 \mathrm{~cm}, 15 \mathrm{~cm}-20 \mathrm{~cm}, \ldots$, [?]60 cm). Based on previous experience, individuals with a DBH less than $4 \mathrm{~cm}$ were regarded as regenerating individuals (Gao et al. 2017). Due to the high mortality of seedlings in tropical forests, the number of seedlings we surveyed was limited, and thus we classified seedlings and saplings with a DBH of less than $5 \mathrm{~cm}$ and a height of less than $4 \mathrm{~m}$ as regenerating individuals.

The mortality rates were analyzed using the exponential function and power function model to fit the size structure of the adult individuals and the height structure of the regenerating individuals (Hett and Loucks 1976). Hett and Loucks assumed a constant probability of mortality over time if the height or DBH structure fit an exponential function and a decrease in mortality over time if a power function provided a better fit. Therefore, we classified the regenerating individuals into groups according to a height interval of $0.5 \mathrm{~m}$ (i.e., $0 \mathrm{~m}-0.5 \mathrm{~m}, 0.5 \mathrm{~m}-1 \mathrm{~m}, \ldots, 3.5 \mathrm{~m}-4 \mathrm{~m}$ ) and combined the size levels of the adults to simulate the mortality at the three sites with the following transformation models involving the exponential or power function. The analysis was performed in IBM SPSS Statistics 20.0 for Windows (SPSS Inc., Chicago, IL, USA).

Power function model

$\log _{\mathrm{e}}(y)=\log _{\mathrm{e}}\left(y_{0}\right)+b x$

Exponential function model

$\log _{\mathrm{e}}(y)=\log _{\mathrm{e}}\left(y_{0}\right)+b \log _{\mathrm{e}}(x)$

where $y$ represents the number of regenerating individuals or adult individuals in any height class $x, y_{0}$ represents the number of individuals in the minimum height class, and $b$ represents the mortality rate (Hett and Loucks 1976).

Species density and richness were used to compare the changes in regeneration patterns across the three sites. These variables were calculated using the total number of regenerating individuals recorded in each plot. Density represents the total number of regenerating individuals in each species. Richness represents the total number of species.

To explore how the regeneration dynamics were related to environmental factors, we explicitly modeled regeneration dynamics using two linear mixed-effect models (LMMs), one modeling the species richness of regenerating individuals and one modeling their total density. In the first LMM, the dependent variable was defined as the species richness in each plot. To eliminate the impacts of sites and plots on the LMMs, we added sites and plots as random variables, and ten environmental factors ( $\mathrm{SOM}, \mathrm{pH}, \mathrm{TN}, \mathrm{AP}, \mathrm{AK}$, elevation, slope, aspect, slope position, canopy density and adult density) were included as fixed variables. The formula of the LMM was as follows:

Linear mixed-effect model 
$Y_{i}=\left[\alpha+\Xi_{\imath} \beta\right]_{\text {fixed part }}+\left[\mu_{\mathrm{S} \mid \pi}+\mu_{\pi}\right]_{\text {random part }}$

where $Y_{i}$ represents the species richness of the $i$ th plot. In the fixed part, $a$ and $\beta$ refer to an intercept and a vector of coefficients of explanatory variables, $x$, respectively. In the random part, $\mu_{S}$ and $\mu_{S \mid \pi}$ represent the spatial autocorrelation at the plot and site scale, respectively (Heming et al. 2016).

With the second LMM, density was also analyzed based on the method used for the first LMM. In both LMMs, only environmental factors with $P<0.05$ were ultimately retained. The analysis was performed with the R package "Ime4".

\section{Results}

3.1 Composition of regenerating individuals and their features at the three study sites 

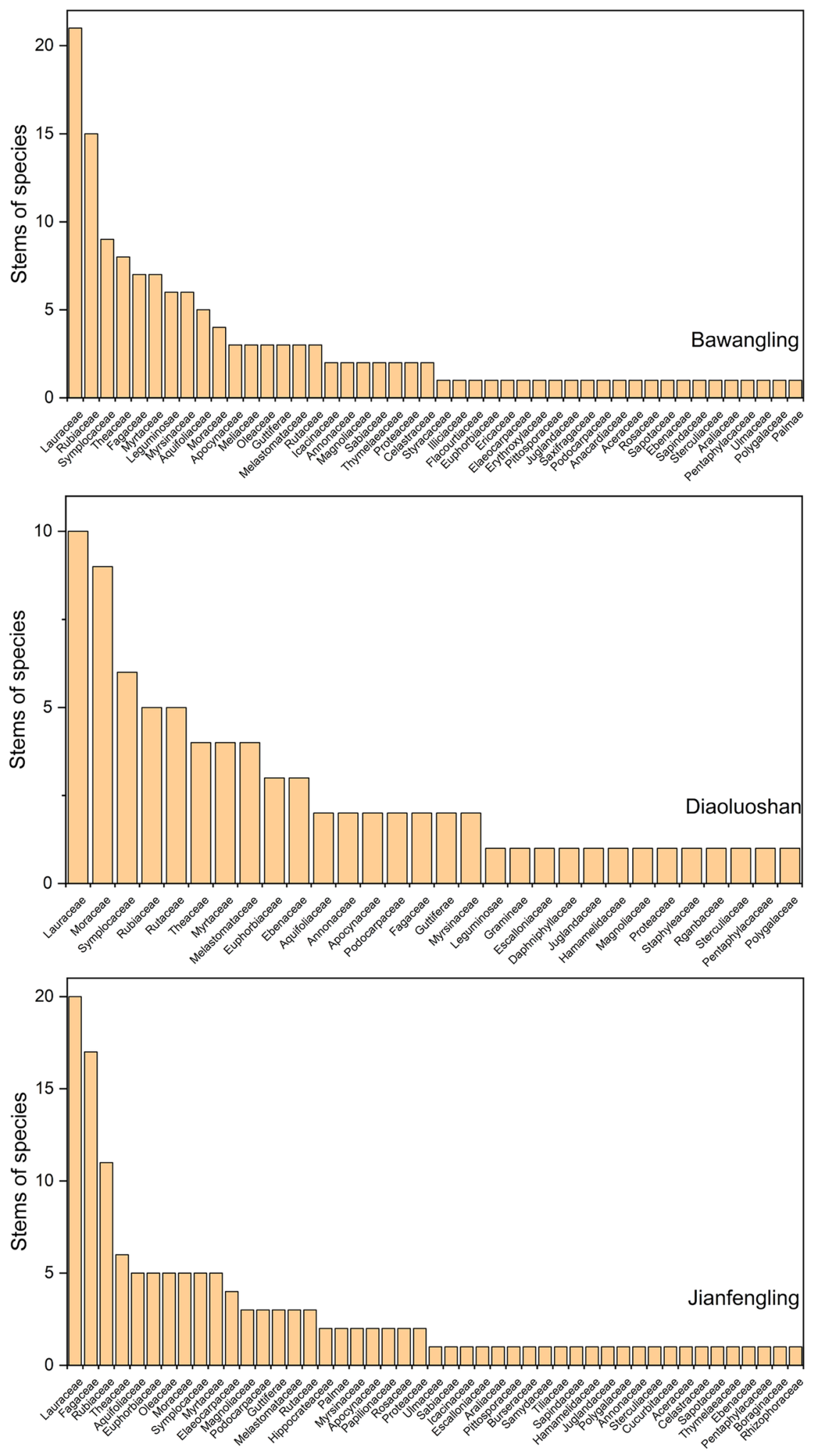

Figure 2. Plant composition of regenerative individuals recorded across the three sites. Family names are 
listed on the $\mathrm{x}$ axis, and the $\mathrm{y}$ axis represents the number of species in each family.

A total of 46 families, 87 genera, and 146 plant species; 30 families, 50 genera, and 81 plant species; and 47 families, 90 genera, and 141 plant species of regenerating individuals were recorded in Bawangling, Diaoluoshan, and Jianfengling, respectively. There were 22 (47.8\%) families in Bawangling, 12 (40\%) families in Diaoluoshan, and 23 (48.9\%) families in Jianfengling with only one plant species (Figure 2). Lauraceae species showed the highest occurrence in these three study areas, with 21 species $(14.4 \%)$ and 8 genera $(9.20 \%) ; 10$ species $(12.3 \%)$ and 5 genera $(10 \%)$; and 20 plant species $(14.2 \%)$ and 7 genera $(7.78 \%)$ in Bawangling, Diaoluoshan, and Jianfengling, respectively.

\subsection{Changes in community structure and mortality across the three sites}

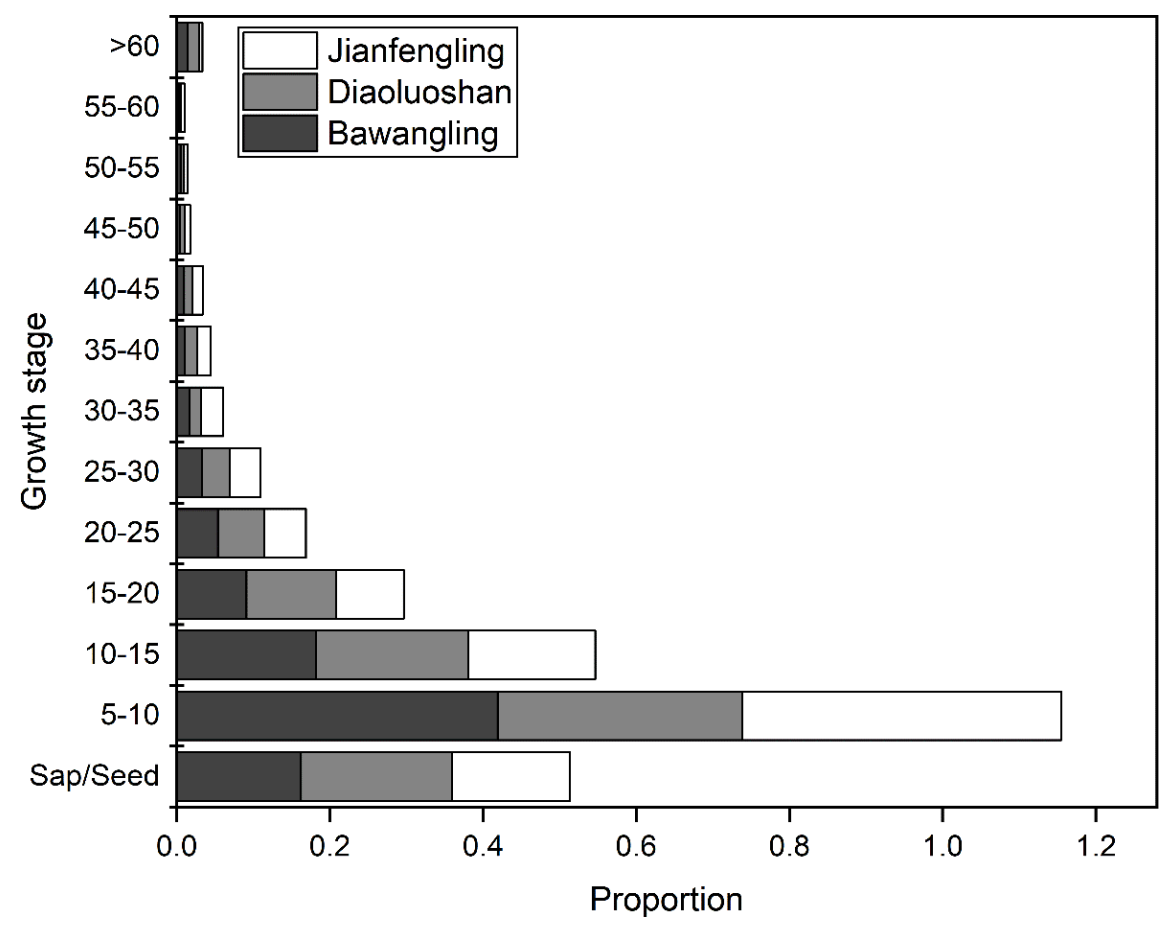

Figure 3. Community structure at the three sites. Seedling: height $<0.5 \mathrm{~m}$; sapling: height $>0.5 \mathrm{~m}$ and diameter at breast height $<5 \mathrm{~cm}$. 

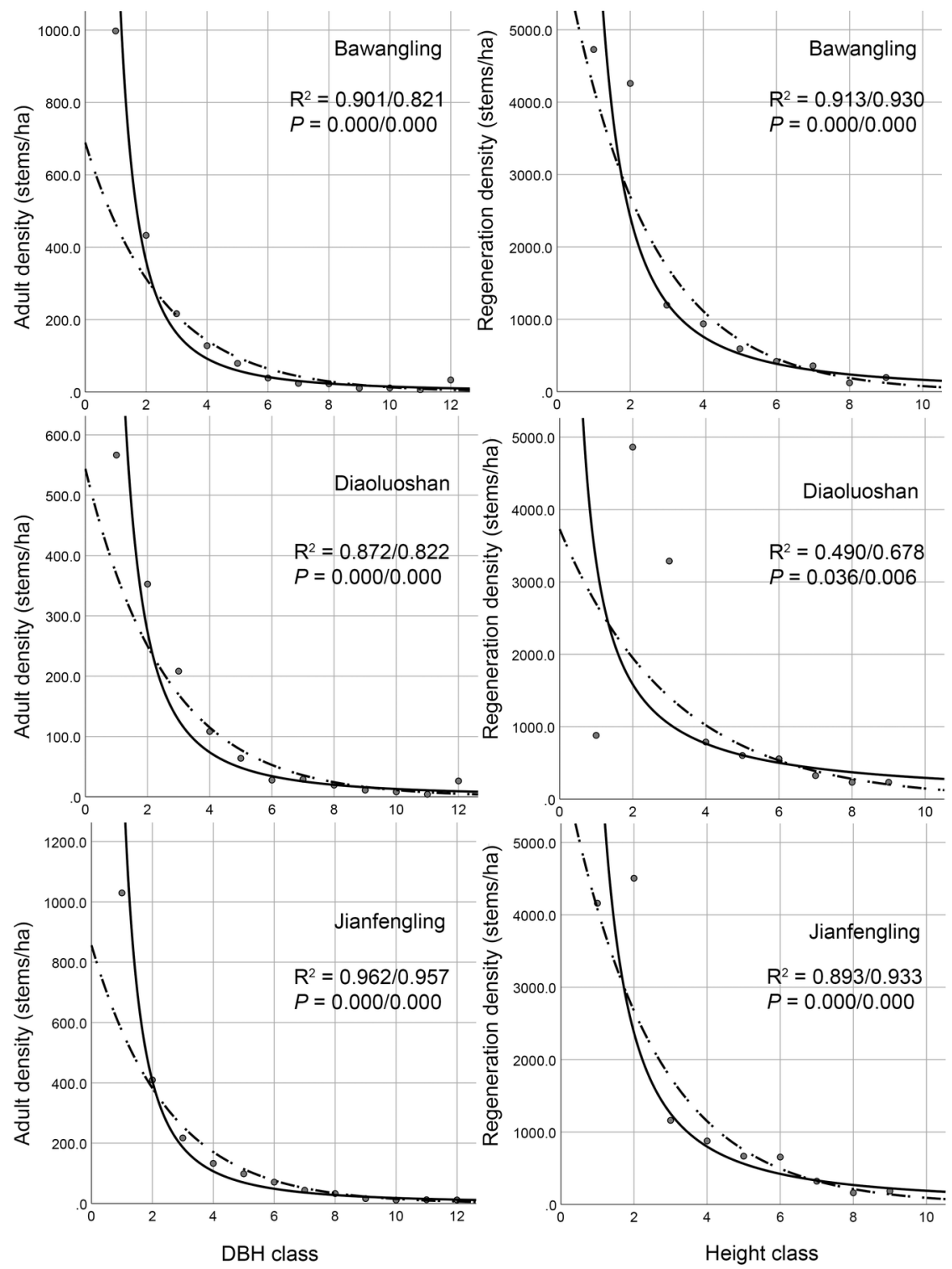

Figure 4. Adult diameter at breast height structure and regenerated individual height structure of $D$. pectinatumcommunities across the three studied sites. The solid and dashed lines represent fitted power and exponential functions, respectively, and their respective $\mathrm{R}^{2}$ and $P$ values are indicated below the site names.

The size structure of the $D$. pectinatum community presented an inverted $\mathrm{J}$ type, and the percentage (less than 20\%) of seedlings/saplings was lower than that of the other growth stages across the three study areas, especially for Bawangling (16.2\%) and Jianfengling (15.4\%) (Figure 3). Both the power and exponential function models fit the changes in adult $(P<0.05)$ and regenerating individual $(P<0.001)$ mortality across the three sites well (Figure 4, Table 2). The adult and regenerating individuals had the lowest mortality rates in Diaoluoshan, followed by Jianfengling, and the highest mortality rates were observed in Bawangling.

Table 2. Power and exponential function model results for the mortality of adults and regenerating individuals across the three sites. 


\begin{tabular}{llllll}
\hline Growth stage & Statistic & Function model & Bawangling & Diaoluoshan & Jianfengling \\
\hline Adult & $R^{2}$ & PFM & 0.901 & 0.872 & 0.962 \\
& & EFM & 0.821 & 0.822 & 0.957 \\
& $F$ & PFM & 91.270 & 68.305 & 254.677 \\
& & EFM & 45.848 & 51.751 & 224.631 \\
& $P$ & PFM & $<0.001^{* * *}$ & $<0.001^{* * *}$ & $<0.001^{* * *}$ \\
& & EFM & $<0.001^{* * *}$ & $<0.001^{* * *}$ & $<0.001^{* * *}$ \\
& $b$ & PFM & -1.968 & -1.891 & -1.928 \\
Regenerating individual & $R^{2}$ & EFM & -0.394 & -0.389 & -0.403 \\
& & PFM & 0.913 & 0.490 & 0.893 \\
& $F$ & EFM & 0.930 & 0.678 & 0.933 \\
& \multirow{2}{*}{$F$} & PFM & 73.851 & 6.724 & 58.336 \\
& & EFM & 92.655 & 14.723 & 97.081 \\
& & PFM & $<0.001$ & $0.036^{*}$ & $<0.001^{* * *}$ \\
& $b$ & EFM & $<0.001^{* * *}$ & $0.006^{* *}$ & $<0.001^{* * *}$ \\
& & PFM & -1.670 & -1.050 & -1.572 \\
& EFM & -0.442 & -0.324 & -0.422 \\
\hline
\end{tabular}

${ }^{*}$ significant $(P<0.05),{ }^{* *}$ significant $(P<0.01),{ }^{* * *}$ significant $(P<0.001)$; PFM represents power function model, EFM represents exponential function model, $b$ represents mortality.

3.3 Changes in the density and species richness of regenerative individuals along elevational gradients
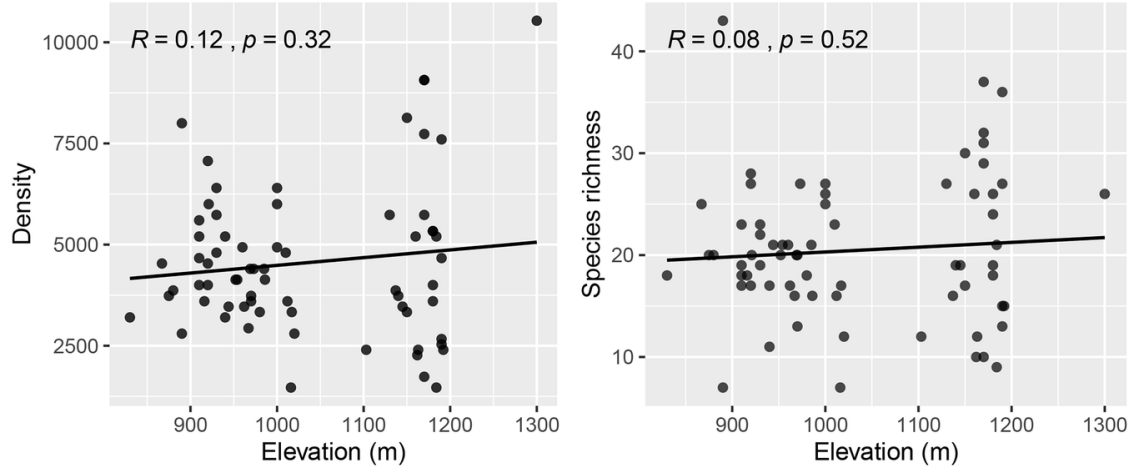

Figure 5. Variation patterns of the denstiy and species richness of regenerative individuals along elevational gradients.

The density and species richness of regenerative individuals showed similar changes with elevation (Figure 5), with peaks limited to middle altitudes (between $900 \mathrm{~m}$ and $1200 \mathrm{~m}$ ). There was no significant correlation with the elevational gradient $(P>0.05)$; that is, the regenerative individuals did not present an increasing or decreasing trend with changes in elevation.

\subsection{Relationship between regeneration dynamics and environmental factors}

Table 2. Exploring the relationships between regeneration dynamics and environmental factors based on linear mixed-effects models 


\begin{tabular}{lllll}
\hline $\begin{array}{l}\text { Environmental } \\
\text { variables }\end{array}$ & $\begin{array}{l}\text { Standardized } \\
\text { regression } \\
\text { coefficient } \pm \mathrm{SE}\end{array}$ & $T$ & $F$ & \\
\hline Density & & & & \\
Intercept & $-109.00 \pm 50.18$ & -2.172 & - & $0.035^{*}$ \\
Elevation & $0.063 \pm 0.023$ & 2.768 & 6.664 & $0.008^{* *}$ \\
Soil total nitrogen & $-11.71 \pm 4.54$ & -2.583 & 5.551 & $0.012^{*}$ \\
Soil available & $0.442 \pm 0.188$ & 2.356 & & $0.022^{*}$ \\
phosphorus & & & 5.142 & $0.027^{*}$ \\
Adult density & $0.007 \pm 0.003$ & 2.268 & - & 0.631 \\
Species richness & & & 8.030 & $0.006^{* *}$ \\
Intercept & $-12.43 \pm 25.69$ & -0.484 & 5.060 & $0.029^{*}$ \\
Soil total nitrogen & $-6.815 \pm 2.405$ & -2.834 & 4.696 & $0.034^{*}$ \\
Elevation & $0.026 \pm 0.012$ & 2.249 & & \\
Canopy density & $25.03 \pm 11.55$ & 2.167 & & \\
\hline
\end{tabular}

${ }^{*}$ significant $(P<0.05),{ }^{* *}$ significant $(P<0.01)$; elevation $(\mathrm{m})$, soil total nitrogen $\left(\mathrm{g} \cdot \mathrm{kg}^{-1}\right)$, soil available potassium $\left(\mathrm{mg} \cdot \mathrm{kg}^{-1}\right)$, adult density (stems $\left.\cdot \mathrm{ha}^{-1}\right)$, and canopy density $(\%)$.

According to the fitting results for both LMMs (Table 2), the density of regenerated individuals was more significantly related to elevation $(P=0.008), \mathrm{TN}(P=0.012), \mathrm{AP}(P=0.022)$, and adult density $(P=0.027)$ than to other environmental factors; the species richness of regenerative individuals was most significantly related to TN $(P=0.061)$, elevation $(P=0.029)$, and canopy density $(P=0.034)$.

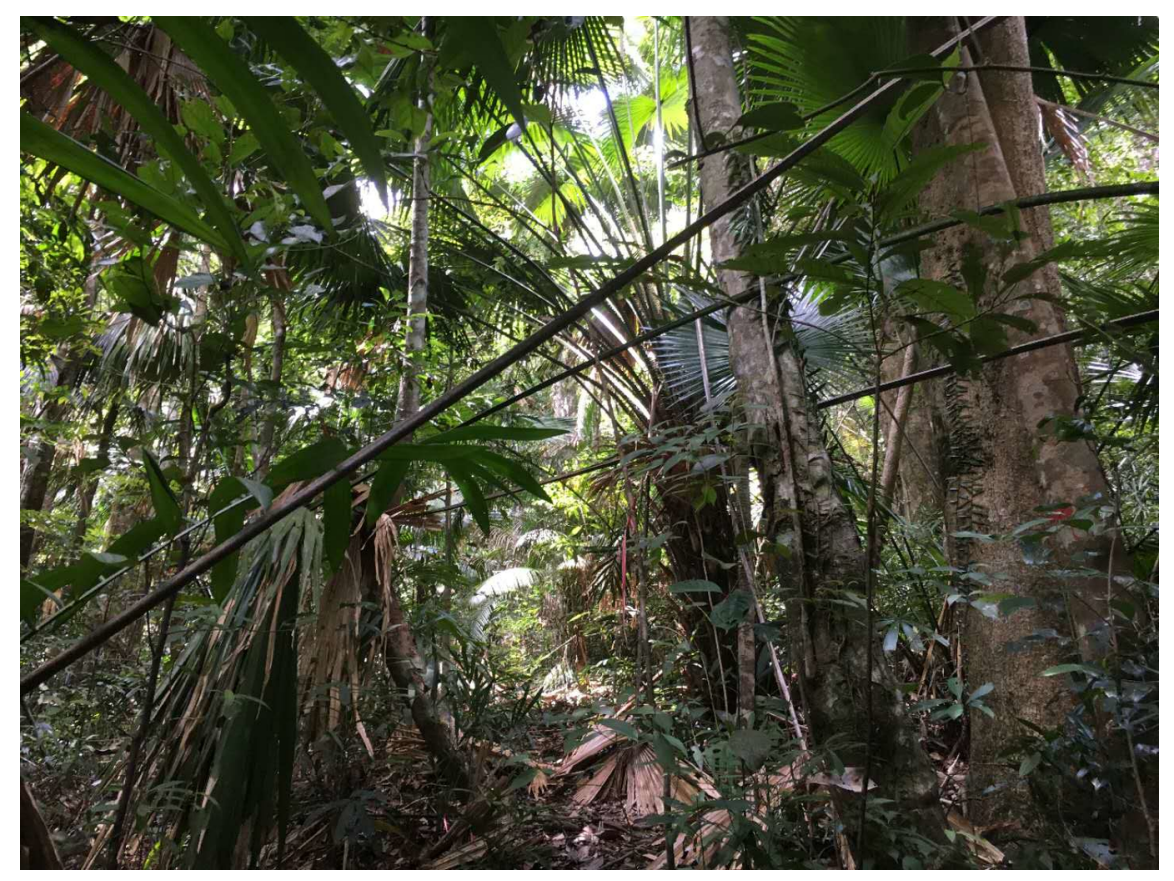

Figure 6 Vegetation in Hainan Island

\section{Discussion}

\subsection{Changes in regeneration dynamics along various environmental axes}


The results showed that the adult and regenerating individuals in Diaoluoshan had the lowest mortality, followed by those in Jianfengling, while the highest mortality among the three D. pectinatumcommunities occurred in Bawangling. The peaks in the density and richness of the regenerative individuals occurred at middle elevations, and there was no obvious change in terms of an increase or a decrease along the elevational gradient. Based on the geographical and climatic factors at the three sites (Table 1), we found that the annual average precipitation $(1806.73 \mathrm{~mm})$ and average temperature $\left(21.89{ }^{\circ} \mathrm{C}\right)$ in Diaoluoshan in the middle of the elevational gradient $(935.97 \mathrm{~m})$ were significantly higher than those in Jianfengling (annual average precipitation and annual average temperature of $1520.33 \mathrm{~mm}$ and $21.75{ }^{\circ} \mathrm{C}$, respectively) in the southwest and Bawangling (annual average precipitation and annual average temperature of 1617.76 $\mathrm{mm}$ and $20.74{ }^{\circ} \mathrm{C}$, respectively) in the northwest. According to these findings, we speculate that on a broad landscape scale, the distribution of regenerative individuals in the $D$. pectinatum community is related to differences in climatic conditions. Variation in precipitation and temperature due to latitude, longitude and elevation may be the dominant cause of the formation of the regeneration dynamic patterns at the three studied sites. Additionally, Diaoluoshan is located in the southeast of Hainan Island. It is affected by a marine climate, which is relatively mild and humid. These superior climatic conditions provide a greater opportunity for successful regeneration than the conditions at other sites. In contrast, Jianfengling and Bawangling, located in the forest hinterland in the southwest and northwest of Hainan Island, respectively, experience lower precipitation and higher air humidity, which may be limiting factors affecting regeneration success; this is especially true for Bawangling, which is higher in elevation than the other sites.

Our results confirm previous reports; for example, some studies have shown that the distribution of vegetation is mainly affected by temperature, precipitation and the combination of both, forming a horizontal (latitudinal and longitudinal) and vertical distribution pattern (Peñuelas et al. 2013). Along meridional gradients, as the distance from the ocean toward inland areas and the regularity of atmospheric circulation and ocean currents change, the vegetation distribution is mainly controlled by water conditions (Crimmins et al. 2011; Vanderwel et al. 2013; Vayreda et al. 2016). Precipitation is considered to be the most important climatic factor affecting tree regeneration. Relatively high precipitation might increase seedling density, especially if future temperatures rise, and the evaporation of the increased surface moisture from the earth may cause a decrease in soil moisture, which may lead to regeneration failure (Jump et al. 2006; Silva et al. 2012). Latitude represents a complex environmental gradient; across latitudes, there are differences in photoperiod, temperature, growing season length, moisture and soil nutrients, which in turn affect the community dynamics and distribution patterns (McKown et al. 2014). In addition, intermediate-elevation areas usually show a moderate expansion phenomenon (Jones et al. 2010; Alatalo et al. 2017; Haider et al. 2011), where suitable temperatures and precipitation are particularly conducive to plant growth and species diversity. Thus, plant species are likely to show aggregation phenomena near mid-elevation areas.

\subsection{Exploring key factors affecting regeneration dynamics along various environmental axes}

By analyzing the relationships between environmental factors and the density and species richness of regenerative individuals, we found that altitude, TN, AP, canopy density, and tree density explained the regeneration dynamics of the community more effectively than other environmental factors. These results indicate that at a community level, habitat preferences related to topography, soil nutrients, and light play a key role in regeneration success and that the J-C effect represented by adult density also affects the regeneration pattern. Previous studies have also shown that species distributions and seedling recruitment in tropical forests are related to topography, soil conditions, and light availability. For example, gaps are important in maintaining species diversity and regeneration in ancient or tropical and subtropical forests (Hubbell et al. 1999; Sapkota et al. 2009). In tropical forests, soil type and topography play an important role in shaping diversity, as both of these factors influence water and nutrient availability (Miyamoto et al. 2003; Phillips et al. 2003).

At the regional scale, elevation usually represents the variation in topography and habitat, which may influence soil fertility and forest gaps by affecting the slope, slope aspect, and slope position (Kraft et al. 2008; Brown et al. 2013). In addition, altitude has also been described as being the most important environmental 
variable by which habitat heterogeneity affects species distribution patterns (Beck and Chey 2008; Rowe and Lidgard 2009). Tree species are particularly sensitive to topographic habitat combinations during the seedling and sapling stages. For example, in a new tropical forest in Ecuador, more than $80 \%$ of new species show one or more topographic habitat associations (Metz 2012). Many studies have confirmed that $\mathrm{N}$ is an important element necessary for plant growth, and its absence may limit the synthesis of chlorophyll and thus weaken photosynthesis in plants (Fortunel et al. 2014; Mueller et al. 2013). The widespread presence of carbon-fixing (Leguminosae ) plants in tropical forests may also be another reason for the close relationship between TN regeneration (Diaz-Gustavo et al. 2015). Previous studies have shown that phosphorus is generally lacking in tropical forest soils, and the total phosphorus content was mostly below $0.8 \mathrm{~g} \mathrm{~kg}^{-1}$ (Cleveland et al. 2011). Phosphorus is also a major element contributing to plant photosynthesis, affecting the survival and causing a uniform distribution among regenerating individuals (Long et al. 2011). Forest gaps have a direct effect on the distribution patterns of seedlings and young trees and help the plants in the lower layers of the forest obtain sunlight (Silva et al. 2012; Sharma et al. 2016). Therefore, the canopy density of forests and the density of regenerating individuals tend to show a close relationship in terms of promoting diversity in the later growth stages of seedlings (Suárez-Esteban et al. 2016). In terms of seed dispersal and germination, the density of parent trees tends to have a positive effect on the density of nearby conspecific seedlings (Lowe and McPeek 2014). The composition of the recruited seedlings is highly dependent on the species composition of the surrounding trees, which promote the successful regeneration of seedlings (Winkler 2011). These results indicate that biological mechanisms (negative density-limiting effects) are also important in promoting the recruitment of tree seedlings.

\section{Conclusions}

Our study found that at a broad landscape scale, the distribution of regenerated individuals in the $D$. pectinatum community is related to differences in climatic conditions. Variation in precipitation and temperature due to latitude, longitude and elevation is the dominant cause for the formation of the regeneration dynamic pattern along distinct environmental axes, and the intermediate environmental conditions in the mid-elevation area contribute to regeneration. At the community level, habitat preferences related to elevational factors, TN, AP and forest gaps play a key role in regeneration success. In addition, biological mechanisms (negative density-limiting effects) also have a particularly important effect on the regeneration of the community.

Funding This work was supported by the Fundamental Research Funds for the Central Non-profit Research Institution of CAF (CAFBB2017ZB004).

Author Contributions Haodong Liu performed the experiments, analyzed the data, and wrote and revised the manuscript. Qiao Chen, Zhiyang Xu, Yunchuan Dai, Yang Liu, Huayu Li, Juan Wang, and Xi Peng analyzed the data. Yongfu Chen conceived and designed the experiments, supervised the study and revised the paper.

Acknowledgments We would like to thank all relevant personnel for their help in data processing. We are grateful to the anonymous reviewers for their constructive comments, which helped to improve this paper. We would also like to extend our thanks to the many local staff members at the Bawangling, Diaoluoshan, and Jianfengling National Nature Reserves who helped us conduct the challenging fieldwork.

Conflicts of Interest The authors declare no conflicts of interest. The manuscript has never been partly or entirely published in or submitted to any other journals. All of the authors agree to the submission of this paper.

Data availability statement All authors agreed to deposit data from this manuscript to a public repository. Data are submitted to Dryad, and DOI number is https://doi.org/10.5061/dryad.nvx0k6dpf.

\section{References}

1. Adler PB, HilleRisLambers JLevine JM (2007) A niche for neutrality. Ecology letters 10(2):95-104. doi:10.1111/j.1461-0248.2006.00996.x. 
2. Alatalo JM, Jägerbrand AK, Juhanson J, Michelsen AĽuptáčik P (2017) Impacts of twenty years of experimental warming on soil carbon, nitrogen, moisture and soil mites across alpine/subarctic tundra communities. Scientific reports 7:44489. doi:10.1038/srep44489.

3. Bai X, Queenborough SA, Wang X, Zhang J, Li B, Yuan Z, Xing D, Lin F, Ye JHao Z (2012) Effects of local biotic neighbors and habitat heterogeneity on tree and shrub seedling survival in an old-growth temperate forest. Oecologia 170(3):755-65. doi:10.1007/s00442-012-2348-2

4. Beck JChey VK (2008) Explaining the elevational diversity pattern of geometrid moths from Borneo: a test of five hypotheses. Journal of Biogeography 35(8):1452-64. doi:10.1111/j.1365-2699.2008.01886.x.

5. Brown C, Burslem D, Illian J, Bao L, Brockelman W, Cao M, Chang L, Dattaraja H, Davies SGunatilleke C (2013) Multispecies coexistence of trees in tropical forests: spatial signals of topographic niche differentiation increase with environmental heterogeneity. Proceedings of the Royal Society B: Biological Sciences 280(1764):20130502. doi:10.1098/rspb.2013.0502.

6. Chesson P (2000) Mechanisms of maintenance of species diversity. Annual review of Ecology and Systematics 31(1):343-66. doi:10.1146/annurev.ecolsys.31.1.343.

7. Cleveland CC, Townsend AR, Taylor P, Alvarez-Clare S, Bustamante MM, Chuyong G, Dobrowski SZ, Grierson P, Harms KEHoulton BZ (2011) Relationships among net primary productivity, nutrients and climate in tropical rain forest: a pan-tropical analysis. Ecology letters 14(9):939-47. doi:10.1111/j.14610248.2011.01711.x.

8. Collins RJCarson WP (2004) The effects of environment and life stage on Quercus abundance in the eastern deciduous forest, USA: are sapling densities most responsive to environmental gradients? For Ecol Manage 201(2-3):241-58. doi:10.1016/j.foreco.2004.06.023.

9. Connell JH (1978) Diversity in tropical rain forests and coral reefs. Science 199(4335):1302-10. doi:10.1126/science.199.4335.1302.

10. Crimmins SM, Dobrowski SZ, Greenberg JA, Abatzoglou JTMynsberge AR (2011) Changes in climatic water balance drive downhill shifts in plant species' optimum elevations. Science 331(6015):324-7. doi:10.1126/science.1199040

11. Dechnik-Vázquez YA, Meave JA, Pérez-García EA, Gallardo-Cruz JARomero-Romero MA (2016) The effect of treefall gaps on the understorey structure and composition of the tropical dry forest of Nizanda, Oaxaca, Mexico: implications for forest regeneration. Journal of Tropical Ecology 32(2):89106. doi:10.1017/s0266467416000092.

12. Diaz-Gustavo N, Martínez-Salvador M, García-Hernández JL, Norzagaray-Campos M, LunaGonzález AGonzález-Ocampo HA (2015) Carbon sequestration of Caesalpinia platyloba S. Watt (Leguminosae)(Lott 1985) in the tropical deciduous forest. PloS one 10(5):e0125478. doi:10.1371/journal.pone.0125478.

13. Ding Y, Zang R, Liu S, He FLetcher SG (2012) Recovery of woody plant diversity in tropical rain forests in southern China after logging and shifting cultivation. Biological Conservation 145(1):225-33. doi:10.1016/j.biocon.2011.11.009

14. Du X, Guo Q, Gao XMa K (2007) Seed rain, soil seed bank, seed loss and regeneration of Castanopsis fargesii (Fagaceae) in a subtropical evergreen broad-leaved forest. Forest Ecology \& Management 238(13):212-9 doi:10.1016/j.foreco.2006.10.018.

15. Fang J, Li Y, Zhu B, Liu GZhou G (2004) Community structures and species richness is the montane rain forest of Jianfengling, Hainan Island, China. Biodiversity Science 12(1):29-43. doi:10.3321/j.issn:1005-0094.2004.01.005.

16. Fortunel C, Paine CT, Fine PV, Kraft NJBaraloto C (2014) Environmental factors predict community functional composition in A mazonian forests. Journal of Ecology 102(1):145-55. doi:10.1111/13652745.12160 .

17. Francisco-Ortega J, Wang ZS, Wang FG, Xing FW, Liu H, Xu H, Xu WX, Luo YB, Song XQGale S (2010) Seed Plant Endemism on Hainan Island: A Framework for Conservation Actions. The Botanical Review 76(3):346-76. doi:10.1007/s12229-010-9055-7.

18. Gao WQ, Ni YY, Xue ZM, Wang XF, Kang FF, Hu J, Gao ZH, Jiang ZPLiu JF (2017) Population structure and regeneration dynamics of Quercus variabilis along latitudinal and longitudinal gradients. 
Ecosphere 8(4):e01737. doi:10.1002/ecs2.1737.

19. Haider S, Alexander JMKueffer C (2011) Elevational distribution limits of non-native species: combining observational and experimental evidence. Plant Ecology \& Diversity 4(4):363-71. doi:10.1080/17550874.2011.637973

20. Heming, Liu, Guochun, Shen, Zunping, Ma, Qingsong, Yang, JianyangXia (2016) Conspecific Leaf Litter-Mediated Effect of Conspecific Adult Neighborhood on Early-Stage Seedling Survival in A Subtropical Forest. Scientific reports 6(1). doi:10.1038/srep37830.

21. Hett JMLoucks OL (1976) Age structure models of balsam fir and eastern hemlock. The Journal of Ecology 64:1029-44.

22. Huang L, Deng Q, Li N, Su YWang T (2014) A set of microsatellite markers developed forDacrydium pectinatum(Podocarpaceae), a vulnerable conifer in China. Conservation Genetics Resources 6(1):1678. doi:10.1007/s12686-013-0037-z

23. Hubbell SP, Foster RB, O'Brien ST, Harms KE, Condit R, Wechsler B, Wright SJDe Lao SL (1999) Light-gap disturbances, recruitment limitation, and tree diversity in a neotropical forest. Science 283(5401):554-7. doi:10.1126/science.283.5401.554.

24. Janzen DH (1970) Herbivores and the number of tree species in tropical forests. The American Naturalist 104(940):501-28. doi:10.2307/2459010

25. Jarcuska B (2009) Growth, survival, density, biomass partitioning and morphological adaptations of natural regeneration in Fagus sylvatica. A review. Dendrobiology 61(1):3-11. doi:10.1139/X08-179

26. Jiang Y, Zang R, Letcher SG, Ding Y, Huang Y, Lu X, Huang J, Liu WZhang Z (2016) Associations between plant composition/diversity and the abiotic environment across six vegetation types in a biodiversity hotspot of Hainan Island, China. Plant \& Soil 403(1-2):21-35. doi:10.1007/s11104-015$2723-\mathrm{y}$

27. Jin Y, Russo SEYu M (2018) Effects of light and topography on regeneration and coexistence of evergreen and deciduous tree species in a Chinese subtropical forest. Journal of Ecology 106(4):163445. doi:10.1111/1365-2745.12911

28. Jones G, Charles M, Bogaard AHodgson J (2010) Crops and weeds: the role of weed functional ecology in the identification of crop husbandry methods. Journal of Archaeological Science 37(1):0-77. doi:10.1016/j.jas.2009.08.017

29. Jump AS, Hunt JMPeñuelas J (2006) Rapid climate change-related growth decline at the southern range edge of Fagus sylvatica. Global Change Biology 12(11):2163-74. doi:10.1111/j.13652486.2006.01250.x.

30. Jurinitz CF, De Oliveira AABruna EM (2013) Abiotic and Biotic Influences on Early-Stage Survival in Two Shade-Tolerant Tree Species in Brazil "s Atlantic Forest. Biotropica 45(6):728-36. doi:10.1111/btp.12058.

31. Keppel G, Prentis P, Biffin E, Hodgskiss P, Tuisese S, Tuiwawa MVLowe AJ (2011) Diversification history and hybridisation of Dacrydium (Podocarpaceae) in remote Oceania. Australian Journal of Botany 59(3):262-73. doi:10.1071/bt10181.

32. KitchingRoger L (2013) Niches and neutrality: community ecology for entomologists. Australian Journal of Entomology 52(1):1-7. doi:10.1111/aen.12015.

33. Kraft NJ, Valencia RAckerly DD (2008) Functional traits and niche-based tree community assembly in an Amazonian forest. Science 322(5901):580-2. doi:10.1126/science.1160662

34. Laurans M, Martin O, Nicolini EVincent G (2012) Functional traits and their plasticity predict tropical trees regeneration niche even among species with intermediate light requirements. Journal of Ecology 100(6):1440-52. doi:10.1111/j.1365-2745.2012.02007.x

35. Long W, Zang RDing Y (2011) Air temperature and soil phosphorus availability correlate with trait differences between two types of tropical cloud forests. Flora-Morphology, Distribution, Functional Ecology of Plants 206(10):896-903. doi:10.1016/j.flora.2011.05.007.

36. Lowe WHMcPeek MA (2014) Is dispersal neutral? Trends in ecology \& evolution 29(8):444-50. doi:10.1016/j.tree.2014.05.009

37. McKown AD, Guy RD, Klápště J, Geraldes A, Friedmann M, Cronk QC, El-Kassaby YA, Mansfield 
SDDouglas CJJNP (2014) Geographical and environmental gradients shape phenotypic trait variation and genetic structure in P opulus trichocarpa. 201(4):1263-76. doi:10.1111/nph.12601.

38. Metz MR (2012) Does habitat specialization by seedlings contribute to the high diversity of a lowland rain forest? Journal of Ecology 100(4):969-79. doi:10.1111/j.1365-2745.2012.01972.x

39. Miller AE, Wilson TL, Sherriff RLWalton J (2017) Warming drives a front of white spruce establishment near western treeline, Alaska. Global Change Biology 23(12):5509-22. doi:10.1111/gcb.13814

40. Miyamoto K, Suzuki E, Kohyama T, Seino T, Mirmanto ESimbolon H (2003) Habitat differentiation among tree species with small-scale variation of humus depth and topography in a tropical heath forest of Central Kalimantan, Indonesia. Journal of Tropical Ecology 19(1):43-54. doi:10.1111/j.14320436.1981.tb01167.x

41. Mueller KE, Hobbie SE, Tilman DReich PB (2013) Effects of plant diversity, N fertilization, and elevated carbon dioxide on grassland soil N cycling in a long-term experiment. Global Change Biology 19(4):1249-61. doi:10.1111/gcb.12096.

42. Myers N, Mittermeier RA, Mittermeier CG, Da Fonseca GAKent J (2000) Biodiversity hotspots for conservation priorities. Nature 403(6772):853. doi:10.1038/35002501

43. Norton DA, Herbert JWBeveridge AE (1988) The ecology of Dacrydium cupressinum: A review. New Zealand Journal of Botany 26(1):37-62. doi:10.1080/0028825X.1988.10410098.

44. Peña-Claros M, Peters E, Justiniano M, Bongers F, Blate GM, Fredericksen TPutz F (2008) Regeneration of commercial tree species following silvicultural treatments in a moist tropical forest. Forest Ecology and Management 255(3-4):1283-93. doi:10.1016/j.foreco.2007.10.033

45. Peñuelas J, Sardans J, Estiarte M, Ogaya R, Carnicer J, Coll M, Barbeta A, Rivas-Ubach A, Llusia JGarbulsky M (2013) Evidence of current impact of climate change on life: a walk from genes to the biosphere. Global Change Biology 19(8):2303-38. doi:10.1111/gcb.12143

46. Phillips OL, Vargas PN, Monteagudo AL, Cruz AP, Zans MEC, Sanchez WG, Yli-Halla MRose S (2003) Habitat association among Amazonian tree species: a landscape-scale approach. Journal of Ecology 91(5):757-75. doi:10.1046/j.1365-2745.2003.00815.x

47. Queenborough SA, Burslem DFRP, Garwood NCValencia R (2009) Taxonomic scale-dependence of habitat niche partitioning and biotic neighbourhood on survival of tropical tree seedlings. Proceedings of the Royal Society Biological Sciences 276(1676):4197-205. doi:10.1098/rspb.2009.0921

48. Rowe RJLidgard S (2009) Elevational gradients and species richness: do methods change pattern perception? Global Ecology and Biogeography 18(2):163-77. doi:10.1111/j.1466-8238.2008.00438.x

49. Sapkota IP, Tigabu MOden PC (2009) Species diversity and regeneration of old-growth seasonally dry Shorea robusta forests following gap formation. Journal of Forestry Research 20(1):7-14. doi:10.1007/s11676-009-0002-6

50. Satoh T, Yoshida T, Koyama S, Yamagami A, Takata M, Doi H, Kurachi T, Hayashi S, Hirobe THata Y (2015) Resource partitioning based on body size contributes to the species diversity of wood-boring beetles and arboreal nesting ants. Insect Conservation \& Diversity 9(1):4-12. doi:10.1111/icad.12136

51. Sharma LN, Grytnes JA, MAaren IEVetaas OR (2016) Do composition and richness of woody plants vary between gaps and closed canopy patches in subtropical forests? Journal of Vegetation Science 27(6):1129-39. doi:10.1111/jvs.12445

52. Silva DE, Mazzella PR, Legay M, Corcket EDupouey JL (2012) Does natural regeneration determine the limit of European beech distribution under climatic stress? Forest Ecology and Management 266:263-72. doi:10.1016/j.foreco.2011.11.031

53. Song X, Hogan JA, Lin L, Wen H, Cao MYang J (2018) Canopy openness and topographic habitat drive tree seedling recruitment after snow damage in an old-growth subtropical forest. Forest Ecology and Management 429:493-502. doi:10.1016/j.foreco.2018.07.038

54. Suarez-Esteban A, Fahrig L, Delibes MFedriani JM (2016) Can anthropogenic linear gaps increase plant abundance and diversity? Landscape Ecology 31(4):721-9. doi:10.1007/s10980-015-0329-7.

55. Suter M, Ramseier D, Connolly JEdwards PJ (2010) Species identity and negative density dependence lead to convergence in designed plant mixtures of twelve species. Basic and Applied Ecology 11(7):62737. doi:10.1016/j.baae.2010.07.008 
56. Vanderwel MC, Lyutsarev VSPurves DW (2013) Climate-related variation in mortality and recruitment determine regional forest-type distributions. Global Ecology and Biogeography 22(11):1192-203. doi:10.1111/geb.12081

57. Vayreda J, Martinez-Vilalta J, Gracia M, Canadell JGRetana J (2016) Anthropogenic-driven rapid shifts in tree distribution lead to increased dominance of broadleaf species. Global Change Biology. doi:10.1111/gcb.13394

58. Vizoso-Arribe O, Diaz-Maroto I, Vila-Lameiro PDiaz-Maroto M (2014) Influence of the canopy in the natural regeneration of Quercus roburin NW Spain. Biologia 69(12):1678-84. doi:10.2478/s11756-0140481-6

59. Winkler E (2011) Dispersal in plants. A population perspective. Annals of Botany 103(3):6-7. doi:10.1111/j.1442-9993.2010.02216.x.

60. Wu C, Chen Y, Peng C, Li ZHong X (2019) Modeling and estimating aboveground biomass of Dacrydium pierrei in China using machine learning with climate change. Journal of Environmental Management 234(234):167-79. doi:10.1016/j.jenvman.2018.12.090.

61. Yan Y, Zhang C, Wang Y, Zhao XVon Gadow K (2015) Drivers of seedling survival in a temperate forest and their relative importance at three stages of succession. Ecology and evolution 5(19):4287-99. doi:10.1002/ece3.1688

62. Zhu H (2017) The Tropical Forests of Southern China and Conservation of Biodiversity. Botanical Review 83(1):87-105. doi:10.1007/s12229-017-9177-2 